\title{
An Intelligent Energy Management Model for a Parallel Hybrid Vehicle Under Combined Loads
}

\author{
Hamid Khayyam, Abbas Z. Kouzani, and Eric J. Hu
}

\begin{abstract}
To exploit the benefits offered by parallel HEVs, an intelligent energy management model is developed and evaluated in this paper. Despite most existing works, the developed model incorporates combined wind/drag, slope, rolling, and accessories loads to minimise the fuel consumption under varying driving conditions. A slope prediction unit is also employed. The engine and the electric motor can output power simultaneously under a heavy-load or a slopped road condition. Two simulation were conducted namely slopped-windyprediction and slopped-windy-prediction-hybrid. The results indicate that the vehicle speed and acceleration is smoother where the hybrid component was included. The average fuel consumption for the first and second simulations were 7.94 and 7.46 liter $/ 100 \mathrm{~km}$, respectively.
\end{abstract}

Keywords: Fuel consumption, intelligent energy management, modeling, friction, parallel hybrid.

\section{INTRODUCTION}

A Hybrid Electric Vehicle (HEV) takes advantage of an internal combustion engine (ICE) and an electric motor to deliver fuel consumption and exhaust emission reduction. HEVs are mainly classified into series, parallel, or series-parallel types. In a series HEV, a generator that is powered by ICE charges the battery or drives the propulsion system using the electric motor. In a parallel HEV, ICE and/or the electric motor can be used to propel the vehicle. In a series-parallel HEV, the features of both the series and parallel types are combined to propel the vehicle.

In this study, a parallel HEV is selected for the development of an intelligent energy management model. The reason why an intelligent energy management model is needed is that the operation range of ICE should be adjusted based on the loading of the vehicle in a parallel HEV. Thus the engine of the parallel HEVs may not be properly preset for its best operating range. Without an intelligent energy management system, high energy efficiency cannot be reached under normal driving conditions.

Langari et al. [1] proposed an intelligent energy management agent for parallel hybrid vehicles. The agent included a driving situation identification component whose role was to assess the driving environment, the driving style of driver, and operating mode of vehicle. Fuzzy logic was

Hamid .Khayyam.,is with the School of Engineering and IT, Deakin University, Geelong, VIC 3217, Australia (e-mail: hkhay@ deakin.edu.au).

Abbas Z. Kouzani.,is with the School of Engineering and IT, Deakin University, Geelong, VIC 3217, Australia (e-mail: kouzani@ deakin.edu.au).

Eric J. Hu.,is with the School of Engineering and IT, Deakin University, Geelong, VIC 3217, Australia (e-mail: erichu@ deakin.edu.au). used to improve energy management. Grelle et al. [2] designed an agent-based architecture to control hybrid vehicles. That architecture was used to design a complex hybrid control environment, in which genetic algorithm was used to optimise energy flow management. Koot [3] formulated a regenerative braking strategy that was based on optimisation techniques. With regenerative braking, a fixed amount of electrical energy could be obtained. The baseline strategy already provided some regeneration, where the regenerative amount increased with the requested load. For higher electric loads, the fuel reduction became smaller. Poursamad et al [4] presented a genetic-fuzzy control strategy for managing energy in hybrid electric vehicles. A fuzzy logic controller was tuned by a genetic algorithm to minimise fuel consumption and emission. The simulation tuning process was executed in three different driving cycles. He et al. [5]presented a fuzzy logic, rule based control strategy for a parallel, hybrid electric vehicle. The energy management optimises engine operational efficiency while maintaining battery state of charge. Fuzzy logic shifting strategy improves the drivability and performance and avoids undesirable frequent shifting.

Despite the ongoing investigation of the energy management approaches for HEVs, there is still a gap. Most of the existing works do not take into account the role of combined wind/drag, slope, rolling, and accessories loads in simulating their energy management strategy and the associated impacts on the fuel consumption of HEV. This paper employs the analysis and simulation approach to develop an Intelligent Energy Management Model (IEMM) for a parallel HEV. IEMM calculates the energy distribution and power flows in the power train of the vehicle and related losses. It indicates the ways to minimises the vehicles' fuel consumption under various driving conditions. IEMM learns when it is run, and makes proper adjustments to the way it operates to ensure that fuel consumption optimisation is achieved.

\section{SPECIFICATION OF VEHICLE AND ENVIRONMENT}

A vehicle engine can be treated as a controlled volume system whose energy balance is given in Equation (1) [6].

$$
\begin{aligned}
\dot{Q}_{\text {combaustio }} & =\left(\dot{Q}_{\text {fuel }}+\dot{Q}_{\text {air }}-\dot{Q}_{\text {exhaus }}\right) \\
& =P_{\text {road friction }}+P_{\text {drag }}+P_{\text {slope }}+P_{\text {accessory }}+P_{\text {driving }}+\dot{Q}_{\text {water oil }}+\dot{Q}_{\text {heatlos: }}
\end{aligned}
$$

In order to include all losses, Equation (1) is reformed into the following equation where the effect of different losses is taken into account by corresponding efficiencies: 


$$
\begin{aligned}
\left(\dot{Q}_{\text {combustion }}\right) \times \eta_{\text {otto }} \times \eta_{\text {fiel-air }} \times \eta_{\text {mechanical }} \times \eta_{\text {heat loss }}=P_{\text {net }} \\
=P_{\text {road-friction }}+P_{\text {drag }}+P_{\text {slope }}+P_{\text {accessory }}+P_{\text {driving }}
\end{aligned}
$$

where: $P_{n e t}=$ Power output of engine

$$
\begin{aligned}
\eta_{\text {otto }} & =\text { Otto cycle efficiency }={ }_{1-\frac{1}{r_{c}^{(\gamma-1)}}}=0.529[7] \\
\eta_{\text {fuel-air }} & =\text { Real fuel air engine efficiency }=0.75[8] \\
\eta_{\text {mechanical }} & =\text { Mechanical efficiency }=0.9[6] \\
\eta_{\text {heat loss }} & =\text { Heat loss efficiency }=0.8
\end{aligned}
$$

To calculate $\dot{Q}_{\text {combaustion }}$ Equation (3) is used:

$$
\dot{Q}_{\text {combustion }}=\dot{m}_{\text {fuel }} \times q_{\text {combustion }}
$$

where $q_{\text {combustion }}$ is the combustion energy. In this model, the fuel is assumed to be $C_{n} H_{1.87 n}$ in [9]. The complete combustion of $C_{8} H_{14.96}$ with $1+k$ percent theoretical air is written as:

$$
\begin{aligned}
& \mathrm{C}_{8} \mathrm{H}_{14.96}+k \times 11.74 \times\left(\mathrm{O}_{2}+3.76\right) \mathrm{N}_{2} \longrightarrow \\
& 8 \mathrm{CO}_{2}+7.48 \mathrm{H}_{2} \mathrm{O}+11.74(\mathrm{k}-1) \mathrm{O}_{2}+11.74 \times 3.76 \times k \times N_{2}
\end{aligned}
$$

If the heat transfer was accurately measured, the released energy would be $109100 \mathrm{~kJ} / \mathrm{kg}$ per 8 mole of $\mathrm{CO}_{2}$ [10]. The result of Equation (4) gives.

$$
q_{\text {combustion }}+\sum n i[h f+\Delta h] i=W_{C . V}+\sum n_{e}\left[h_{f}+\Delta h\right]_{e}
$$

Where:

$\sum n_{i}\left[h_{f}+\Delta h\right]_{i}=h_{f} C_{8} H_{14.96}+1.2 \times 11.74\left(O_{2}+3.76 \times N_{2}\right)$

$=793.23 \mathrm{~kJ} / \mathrm{kg}$ and

$\sum n_{e}\left[h_{f}+\Delta h\right] e=8 \mathrm{CO}_{2}\left[h_{f}+\Delta_{h}\right] \mathrm{CO}_{2}+7.48 \mathrm{H}_{2} \mathrm{O}\left[h_{f}+\Delta_{h}\right] \mathrm{H}_{2} \mathrm{O}+$

$11.74 \times(0.2) O_{2}\left[\Delta_{h}\right] O_{2}+11.74 \times 3.76 \times 1.2 \times N_{2}\left[\Delta_{h}\right] N_{2}$

$=37219.70 \mathrm{~kJ} / \mathrm{kg}$ and $W_{C . V}=0$

$$
q_{\text {combustion }}=|-37219.70+793.23|=38017.93 \mathrm{~kJ} / \mathrm{kg}
$$

Substituting the terms stated in Table 1, the mass flow rate fuel consumption of the vehicle can be calculated as follows :

$$
\dot{m}_{\text {fuel }}=\frac{P_{\text {road-friction }}+P_{\text {drag }}+P_{\text {slope }}+P_{\text {accessory }}+P_{\text {driving }}}{\left(q_{\text {combustion }}\right) \times \eta_{\text {otto }} \times \eta_{\text {fuel-air }} \times \eta_{\text {mechanical }} \times \eta_{\text {heat loss }}}
$$

The total fuel consumption in this process is:

$$
m_{\text {fuel }}=\int_{0}^{T} \dot{m}_{\text {fuel }} \times d t
$$

where $\mathrm{T}$ is the total numbers of steps involved in the simulation. The equation (2) can be transformed into:

\begin{tabular}{|c|c|c|c|}
\hline Description & Type & Symbol & Value \\
\hline \multicolumn{4}{|l|}{ Combustion } \\
\hline Enthalpy of formation & E-F & $\bar{h}_{f}^{\circ}$ & $\begin{array}{l}\text { Thermodynamic tables } \\
\text { of [9] }\end{array}$ \\
\hline Sensible formation & E-F & $\Delta \bar{h}$ & $\begin{array}{l}\text { Thermodynamic tables } \\
\text { of [9] }\end{array}$ \\
\hline combustion energy & E-F & $q_{\text {combustion }}$ & $38017 \mathrm{~kJ} / \mathrm{kg}$ \\
\hline $\begin{array}{l}\text { mass flow rate of fuel } \\
\text { combustion }\end{array}$ & $\mathrm{V}-\mathrm{O}$ & $\dot{m}_{\text {fuel }}$ & $\mathrm{kg} / \mathrm{s}$ \\
\hline Temperature of fuel & V-S & $T_{\text {fuel }}$ & $27^{\circ} \mathrm{C}$ \\
\hline Temperature of air & $\mathrm{V}-\mathrm{S}$ & $T_{a i r}$ & $27^{\circ} \mathrm{C}$ \\
\hline $\begin{array}{l}\text { Temperature of } \\
\text { exhaust }\end{array}$ & V-S & $T_{\text {exhaust }}$ & $450^{\circ} \mathrm{C}$ \\
\hline $\begin{array}{l}\text { Engine compression } \\
\text { ratio }\end{array}$ & E-F & $r_{c}$ & 8.6 \\
\hline Air compression ratio & E-F & $\gamma$ & 1.35 \\
\hline $\begin{array}{l}\text { Ratio of nitrogen per } \\
\text { oxygen }\end{array}$ & E-F & $r_{N 2 / O 2}$ & 3.76 \\
\hline Excess air & $\mathrm{V}-\mathrm{O}$ & $E_{\text {excessair }}$ & $20 \%$ \\
\hline \multicolumn{4}{|l|}{ Road } \\
\hline Road friction & E-F & $F_{\text {friction }}$ & $C_{\text {rolling }} m g \cos \Phi$ \\
\hline $\begin{array}{ll}\text { Road } & \text { friction } \\
\text { coefficient } & \end{array}$ & E-F & $C_{\text {rolling }}$ & 0.01 \\
\hline Gravity acceleration & E-F & $g$ & $9.8 \mathrm{~m} / \mathrm{s}^{2}$ \\
\hline Vehicle velocity & $\mathrm{V}-\mathrm{O}$ & $V_{1}$ & $16.6 \mathrm{~m} / \mathrm{s}$ \\
\hline Vehicle angle & $\mathrm{V}-\mathrm{O}$ & $\theta_{1}$ & $0^{\circ}$ \\
\hline \multicolumn{4}{|l|}{ Drag } \\
\hline Drag friction & E-F & $F_{\text {drag }}$ & $C_{d r a g}(\theta) \times \frac{1}{2} \rho V^{2} A(\theta)$ \\
\hline Wind angle of attack & E-F & $\theta_{2}$ & $\begin{array}{l}0^{\circ}(\text { front attack }) \\
90^{\circ}(\text { side attack }) \\
180^{\circ}(\text { rear attack })\end{array}$ \\
\hline Wind velocity & E-F & $V_{2}$ & $20,15,10 \mathrm{~m} / \mathrm{s}$ \\
\hline $\begin{array}{l}\text { Result wind and } \\
\text { vehicle angle }\end{array}$ & $\mathrm{V}-\mathrm{O}$ & $\theta$ & $\begin{array}{c}\text { Calculate in simulation } \\
\text { IEMM }\end{array}$ \\
\hline $\begin{array}{l}\text { Result of wind and } \\
\text { vehicle speed }\end{array}$ & $\mathrm{V}-\mathrm{O}$ & $V_{t}$ & $\begin{array}{l}\text { Calculate in simulation } \\
\text { IEMM }\end{array}$ \\
\hline $\begin{array}{l}\text { Result of wind and } \\
\text { vehicle speed }\end{array}$ & $\mathrm{V}-\mathrm{O}$ & $V_{t-1}$ & $\begin{array}{l}\text { Calculate in simulation } \\
\text { IEMM }\end{array}$ \\
\hline $\begin{array}{l}\text { Drag coefficient } \\
\text { (By simulation ) }\end{array}$ & V-S & $C_{\text {drag }}(\theta)$ & $\begin{array}{l}-(0.00005) \times(\theta) \\
+0.0097 \times(\theta)+0.31\end{array}$ \\
\hline Front surface area & $\mathrm{V}-\mathrm{S}$ & $A(\theta)$ & $1.8 \times 1 / \cos (\theta)$ \\
\hline $\begin{array}{l}\text { Vehicle }+ \text { passenger } \\
\text { mass }\end{array}$ & $\mathrm{V}-\mathrm{O}$ & $m$ & $1280 \mathrm{~kg}$ \\
\hline Air density & E-F & $\rho$ & $1.225 \mathrm{~kg} / \mathrm{m}^{3}$ \\
\hline \multicolumn{4}{|l|}{ Slope } \\
\hline Slope friction & $\mathrm{R}-\mathrm{O}$ & $F_{\text {slope }}$ & $m g \sin \Phi$ \\
\hline Road slope angle & $\mathrm{R}-\mathrm{O}$ & $\Phi$ & $-30^{\circ}<$ Step $<30^{\circ}$ \\
\hline $\begin{array}{l}\text { Radius of Comfort } \\
\text { requirement }\end{array}$ & $\mathrm{R}-\mathrm{O}$ & $R$ & $100 \mathrm{~m}$ \\
\hline \multicolumn{4}{|l|}{ Accessory } \\
\hline Accessory & $\mathrm{V}-\mathrm{O}$ & $P_{\text {Acessory }}$ & 3000 watt \\
\hline
\end{tabular}
$P_{n e t}=\left[F_{\text {friction }}+F_{\text {drag }}+F_{\text {slope }}+F_{\text {accessory }}\right] \times V_{t}+\frac{1}{\Delta t}\left[1 / 2 \times m \times\left(V_{t-1}^{2}-V_{t}^{2}\right)\right]$

The symbols given in these equations are described in Table I. The acceleration of the vehicle in $\Delta t$ time can be calculated as:

$$
a_{t}=\frac{V_{t}-V_{t-1}}{\Delta t}=\frac{d V}{d t}
$$

Also, the distance of traversed by vehicle in $\Delta t$ is:

$$
X_{t}=\frac{1}{2} \times a_{t} \times \Delta t^{2}+V_{t-1} \times \Delta t
$$

TABLE I

PARAMETERS INVOLVED IN ENERGY BALANCE EQUATION

\section{Simulation Methodology}

A. Slope

In real world, when a road is designed, several geometric design methods could be used [11] to smoothen physical slope of the road. A popular method is called "vertical curve comfort" that provides a smooth passage vertical curve. Fig. 1. demonstrates the components of a 
parabolic vertical curve and Equation (11-13) gives the formulae used to calculate the middle ordinate, intermediate coordinates, and the distance from either end of the curve. The length of the vertical curve $(\mathrm{m})$ for a $1 \%$ change of grade $(\mathrm{m} / \mathrm{unit} \%)$ is given as follows:

$$
K=\frac{L}{A},
$$

where, $\mathrm{L}=$ length of vertical curve, and $\mathrm{A}=$ algebraic difference of grade (\%) $K$ (see Table II).

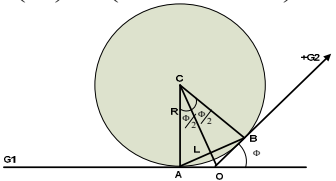

Fig 1. Components of a parabolic vertical curve. Table II

SAG VERTICAL CURVE COMFORT CRITERIA [11]

\begin{tabular}{lll}
\hline \hline $\begin{array}{l}\text { Design speed } \\
(\mathrm{km} / \mathrm{h})\end{array}$ & \multicolumn{1}{c}{$\mathrm{K}=0.05 \mathrm{~g}$} & $\mathrm{a}=0.10 \mathrm{~g}$ \\
\hline 40 & 3 & 1.5 \\
50 & 4 & 2 \\
60 & 6 & 3 \\
\hline $\mathrm{a}=$ acceleration & &
\end{tabular}

Also, for design purposes, a vertical curve can be plotted using a circular curve of radius $R$ which approximates a parabolic curve by the relationship:

$$
R=100 \times K
$$

In our work, $K$ is chosen as 3 , and thus for the acceleration of $0.1 \mathrm{~g}\left(0.98 \mathrm{~m} / \mathrm{s}^{2}\right)$, the speed of should be 60 $\mathrm{km} / \mathrm{h}(16.6 \mathrm{~m} / \mathrm{s})$. As shown in Fig. 1, the distances $O A$ and $O B$ are equal, and can be calculated as follows:

$$
O A=O B=\operatorname{Tan} \frac{\Phi}{2} \times R
$$

\section{B. Model}

The overview of the developed power flow analysis IEMM is shown in Fig 2.

B.1. Conventional vehicle: A driver first determines the drive strategy, selects the engine specifications, starts the vehicle motion, and controls the mass flow rate of fuel in to ICE by changing the pedal, gear, brake, and clutch.

B.2. Hybrid: First the generator takes mechanical energy from the planetary gear and then converts it to electric energy, and then directs it to the inverter. The inverter transmits the electric energy to the battery for a desired time. This backup chemical energy is stored in the battery until the inverter requests to operate the EM. The EM then produces the mechanical energy combined with powertrain.

B.3. IEMM: This represents the proposed simulation methodology as follows:

1. Slope Prediction Unit (SPU): This unit employs an imaging sensor and a vision algorithm to calculate the slope angle of the road ahead within the distance of 50 meters away from the vehicle, and forward this information to IEMM.

2. Friction Management Unit (FMU):

i. Current Road Slope Module (CRSM): This module specifies the actual slope angle of the road at the current location of the vehicle. ii. Road Friction Module (RFM): This module gives road friction coefficient, gravity acceleration, and motion angle.

iii. Combustion Module (CM): This module employs the combustion process from the vehicle as described in Equation (3), and calculates and returns the amount of combustion energy needed.

iv. Wind Drag Module (WDM): This module provides the following wind parameters: wind speed, wind direction, and drag coefficient.

v. Accessory Module (AM): This module represents the accessories embedded within the vehicle such as electrical devices and air conditioning.

vi. Vehicle Efficiencies Module (VEM): This module defines the values of the otto cycle, real fuel air engine, mechanical and heat loss efficiencies.

3. Battery State of Charge (BSOC): This module provides the amount of the current, temperature and voltage of the battery continuously.

C. Algorithm

C.1. IEMM Algorithm: The overview of the simulation algorithm for IEMM is displayed in Fig. 3. The simulation starts with initialising several variables including normal power and primal kinetic energy for a moving vehicle. The data include arrays of 72000 elements (steps). One iteration occurs in each step representing the time interval of 0.05 sec. Then the slope prediction data is retrieved from SPU. If the predicted slope angle is different from the current slope angle, STI block increases or decreases the power. Next, the vehicle/environment/friction data is retrieved from FMU. If the current total friction energy is different from the energy associated with the slope prediction, FTI block is triggered calculating the amount of power for all frictions. Otherwise, OPP block is entered. OPP optimises the fuel consumption with respect to the vehicle/efficiencies, speed, acceleration, and gear data. The results of OPP are compared against the drive strategy. If the comparison is satisfied then these data will be forwarded to the next block where they overwrite the results of the previous iteration. Otherwise, the power of engine is corrected by decreasing or increasing it in the increase/decrease power block. Once either of speed or acceleration is found greater than the desired limit, then the engine power is reduced. When either of speed or acceleration becomes smaller than the desired limit, the engine power is increased. In the assignment block, old data is overwritten with the new data.

C.2. Inverter Algorithm: The Inverter algorithm, shown in Fig 4, synchronises the battery with EM, Gen. With regard to the battery SOC and IEMM Interpreter Load (IIL), inverter starts charging or discharging the battery in each time. It then informs the IEMM about its result via BSOC. Table III shows a list of if-then rules that represent the propulsion balance IIL energy management strategy. If SOC is high, and at times of high load, the generator can be 


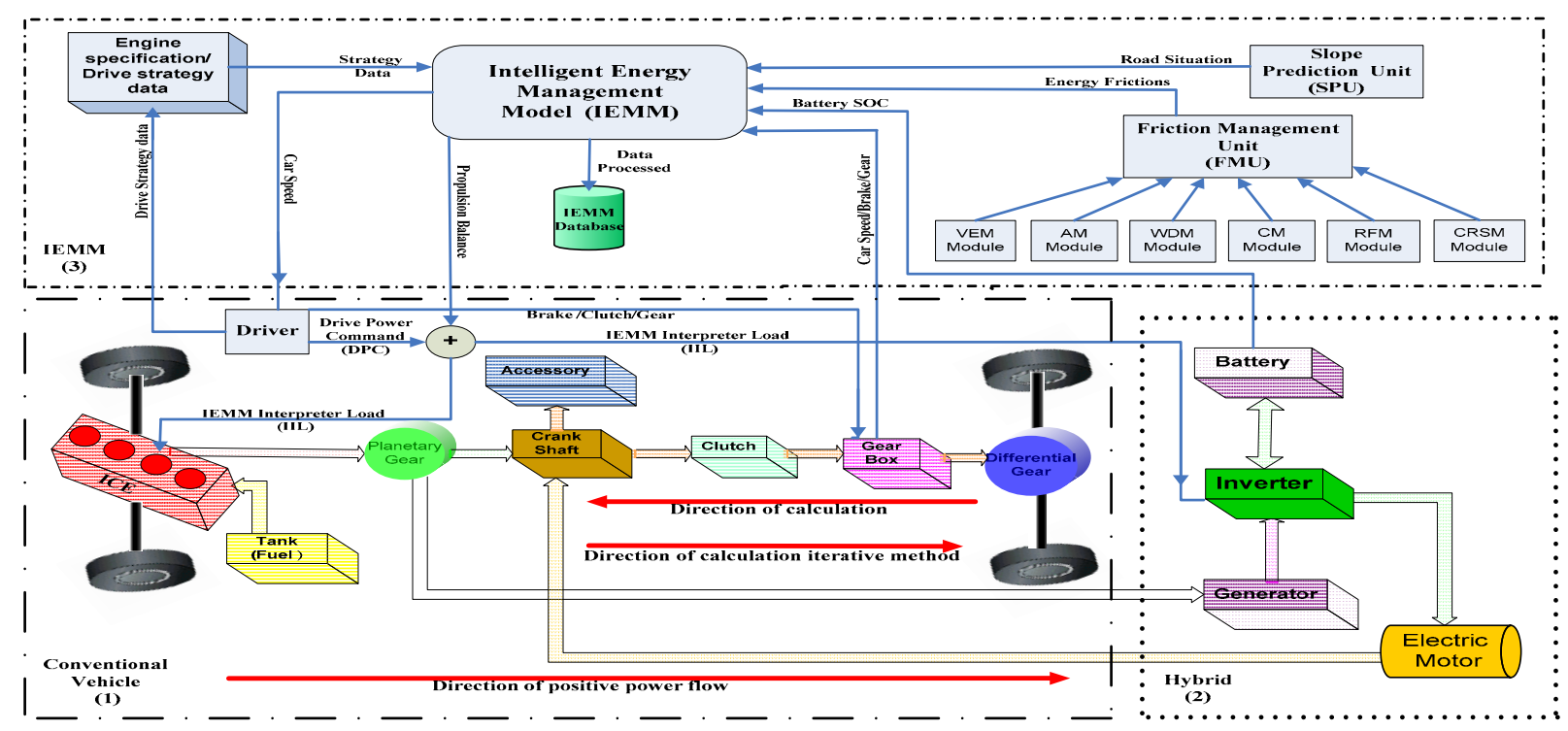

Fig. 2. Overview of the developed power flow analysis for HEV.

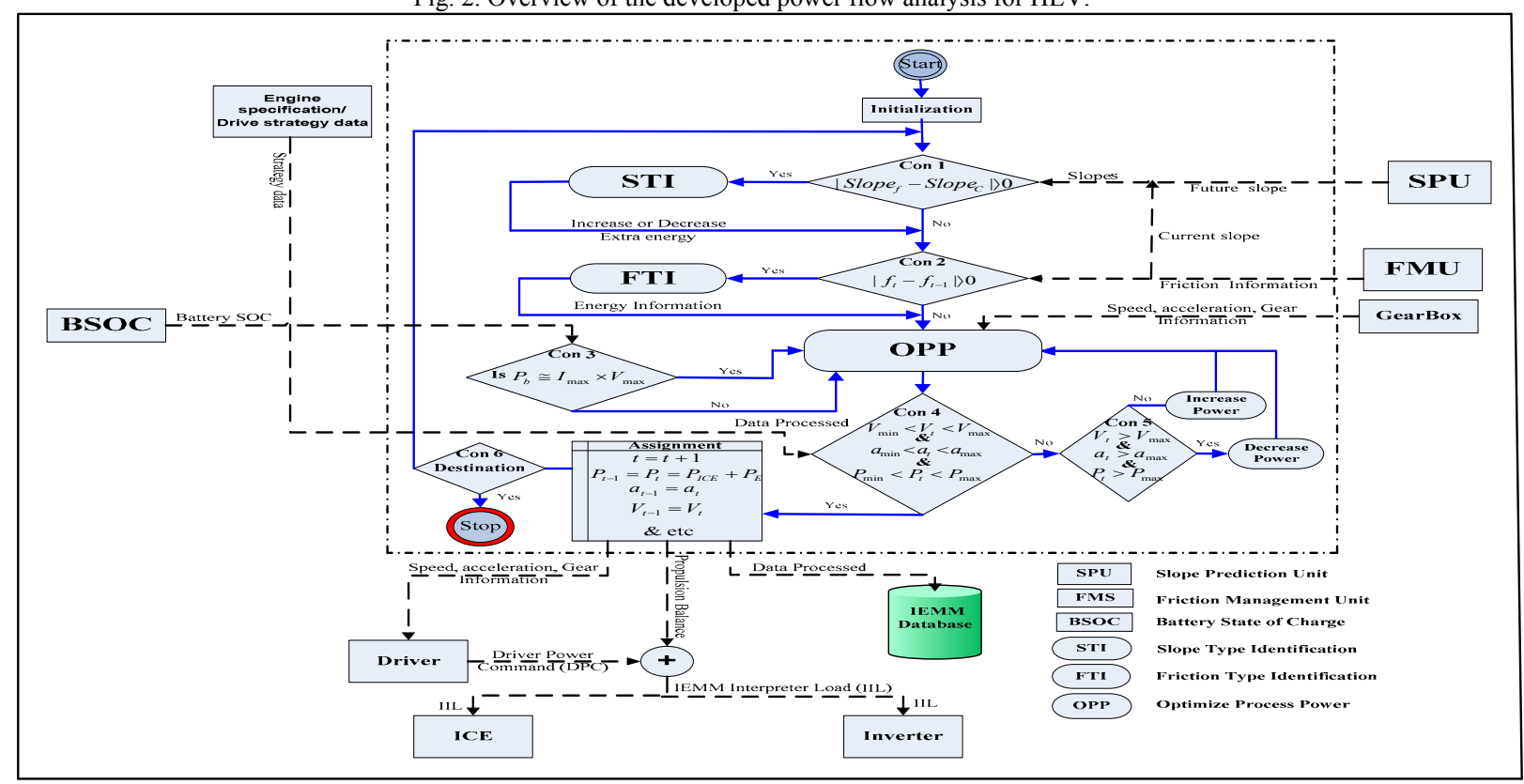

Fig .3. Overview of the simulation algorithm for the IEMM.

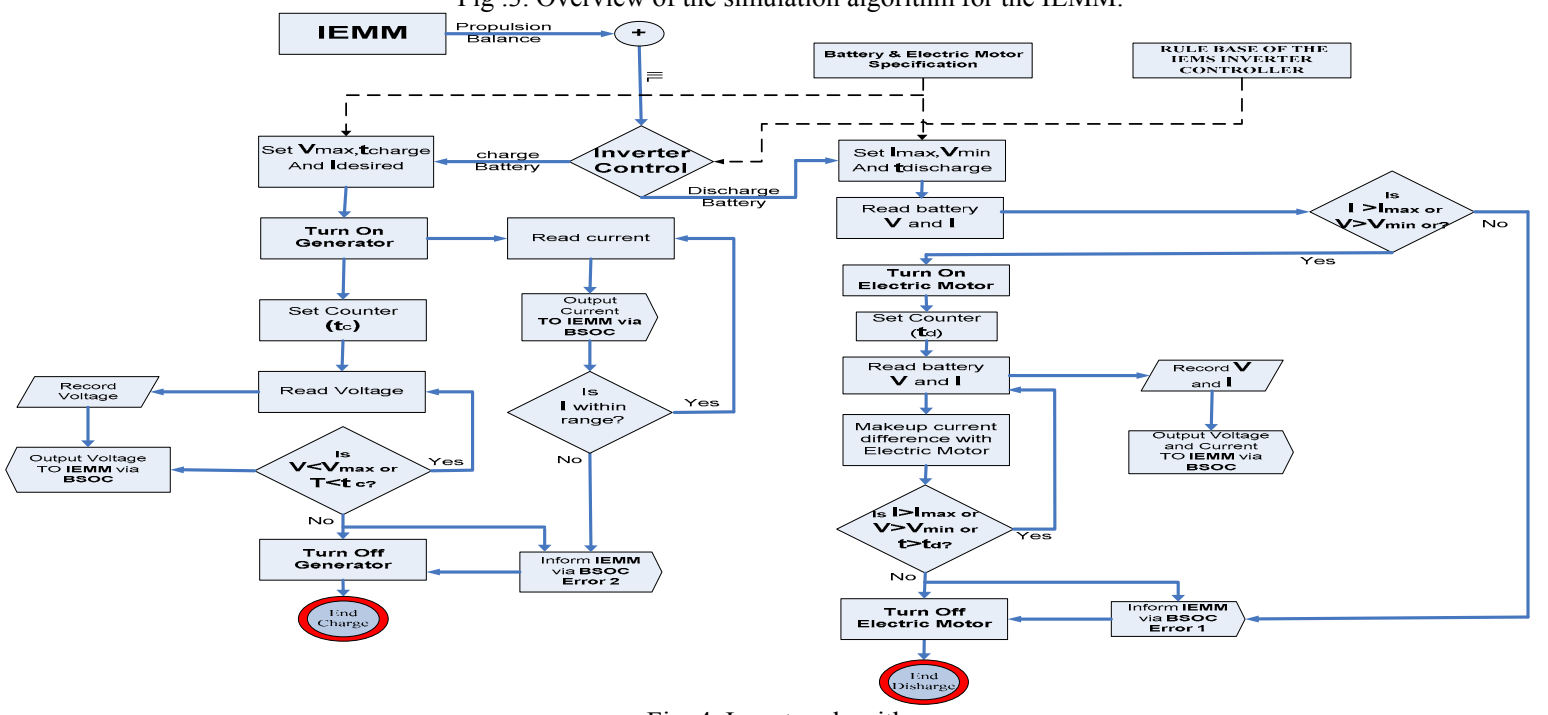

Fig .4. Inverter algorithm. 
switched off and EM can provide mechanical power via the battery by the inverter's instruction.

Table III

RULE BASE OF THE INVERTER ALGORITHM

\begin{tabular}{|c|c|c|c|c|}
\hline NO & $\begin{array}{c}\text { If } \\
\text { SOC }\end{array}$ & $\begin{array}{l}\text { And } \\
\text { IIL }\end{array}$ & $\begin{array}{l}\text { Then } \\
\text { Gen }\end{array}$ & $\begin{array}{l}\text { And } \\
\text { EM }\end{array}$ \\
\hline 1 & High & High & Off & On \\
\hline 2 & High & Normal & Off & On \\
\hline 3 & High & Low & Off & On \\
\hline 4 & Normal & High & Off & On \\
\hline 5 & Normal & Normal & Off & On \\
\hline 6 & Normal & Low & On & Off \\
\hline 7 & Low & High & On & Off \\
\hline 8 & Low & Normal & On & Off \\
\hline 9 & Low & Low & On & Off \\
\hline
\end{tabular}

D. Drive Strategy

Moreover, in this work, we have considered a vehicle with the engine specification as given in Table IV. TABLE IV

ENGINE SPECIFICATION

\begin{tabular}{cccc}
\hline \hline Parameters & Min & Max & Average \\
\hline Engine size (litre) & ---- & 1.9 & -------- \\
RMP $($ rev / min $)$ & 4000 & 6000 & 4500 \\
Engine power $(\mathrm{kW})$ & 9.9 & 120 & 12 \\
\hline \hline
\end{tabular}

We have formulated a set of rules called "Drive Strategy" shown in Table V.

TABLE V

DRIVE STRATEGY PARAMETERS

\begin{tabular}{cccc}
\hline \hline Parameters & Min & Max & Average \\
\hline Speed $(m / s)$ & 16.38 & 16.94 & 16.66 \\
Acceleration $\left(m / s^{2}\right)$ & -0.98 & 0.98 & 0.5 \\
Travel Time $(s)$ & $------~$ & 3600 & 0.05 \\
Travel Distance $m$ & & 6000 & \\
\hline \hline
\end{tabular}

Using the fuel map diagram presented in [9], the relation between the mechanical power above $70 \mathrm{~kW}$ and the fuel rate for each engine speed is nonlinear that can be simulated with the function $y=0.0002 x^{2}+0.0481 x+1.2557$. More than $70 \mathrm{~kW}$ is considered as uneconomic.

\section{E. Battery and Electric Motor}

Table VI provides the specifications of the battery and EM. The battery efficiency is considered as:

$$
\eta_{\text {Batt }}=2547600 / 2881008=88 \%
$$

TABLE VI

BATTERY AND ELECTRIC MOTOR SPICIFICATIONS

\begin{tabular}{|c|c|c|}
\hline Feature & Symbol & Type \\
\hline \multicolumn{3}{|l|}{ Battery } \\
\hline \multirow{2}{*}{$\begin{array}{c}\text { Cells per module } \\
\text { Total Volts }\end{array}$} & \multirow{5}{*}{$\mathbf{V} \max$} & 6 \\
\hline & & 273.6 \\
\hline Capacity (Amp hours) & & 6.5 \\
\hline Capacity (Watt hours) & & 1778.4 \\
\hline Charge & & $1778.4 * 3600=6402240$ \\
\hline Capacity Charge (joule) & \multirow{3}{*}{ tc } & $66402240 * 40 \%=2881008$ \\
\hline Time charge (second) & & 500 \\
\hline Charge & & $2881008 / 500=5762$ \\
\hline Current desired (Amp) & Ides & 21.06 \\
\hline \multicolumn{3}{|l|}{ Electric Motor } \\
\hline Operating Voltage (V) & $V_{\min }$ & 273 \\
\hline Power & & 33000 \\
\hline Net Power & & $33000 * 40.1=13200$ \\
\hline Current & Imax & $13200 / 273.6=48.36$ \\
\hline Current $\quad(A m p /$ hour $)$ & & $48.36 /(6.5 * 40.1)=18.6$ \\
\hline Max work time (second) & $\mathbf{t d}$ & $3600 / 18.6=193$ \\
\hline
\end{tabular}

\section{RESUlt AND DiscUSSIONS}

\section{A. Simulations}

A.1. Simulation 1: IEMM was tested on a set of data associated with a slopped-windy-prediction condition in which the Hybrid section was not included. The road was set to be slopped with various slope angles within the range $20^{\circ} \leq \varnothing \leq+25^{\circ}$. Moreover, the environmental wind was assumed to be non-zero. The wind angle of attack was varied as follows: $\theta_{2}=0^{\circ}, \theta_{2}=90^{\circ}$, and $\theta_{2}=180^{\circ}$. Considering the wind velocity, however, four different conditions were implemented: $\mathrm{V}_{2}=0, \mathrm{~V}_{2}=10, \mathrm{~V}_{2}=15, \mathrm{~V}_{2}=20$. SPU monitors the slope ahead within a 50 meter distance. The following parameters were considered: road-friction, combustion, and constant accessory (Table I). Fig. 5 illustrates the slope angle, wind-speed as well as prediction slope angle data used in this simulation. The horizontal axis shows the 72000 simulation steps, while the vertical axis displays the slope (road) angle (a), and the wind-speed (b).

A.2. Simulation 2: IEMM was tested on a set of data associated with a slopped-windy-prediction employing the Hybrid section. The management of the battery, EM, and Gen is conducted by the Inverter algorithm. This enables ICE and EM to output power simultaneously when the load is greater than $20 \mathrm{~kW}$ or a slope of greater than $10^{\circ}$ is climbed by the vehicle. The following parameters were also considered: road-friction, combustion, and constant accessory. The prediction slope angle data is similar to the slope angle data.

\section{B. Discussions}

B.1. Simulation Result 1: The power and fuel consumption results for the first simulation are shown in Fig. 6. Initially $8635 \mathrm{~W}$ of energy is given to the vehicle so that the initial speed of $16.6 \mathrm{~m} / \mathrm{s}$ is achieved. The energy consumption remained constant at $8635 \mathrm{~W}$ where the condition was flat-windless (e.g. Steps 0-9000). Depending on the condition of the road slope angle, the wind speed, and angle of attack, the power consumption varied as shown in Fig. 6 . The vehicle was informed about any slope ahead by SPU. IEMM uses this information and increases $\dot{m}$ about 50 meters prior to reaching the hill. In addition, IEMM decreases $\dot{m}$ about 50 meters prior to reaching the top of the hill because the vehicle would have adequate kinetic energy to pass the hill. Fig. 6 shows that the slope friction that is an unexpected environmental friction has a significant impact on the fuel consumption. The reason is that it requires more fuel in a transit time. Slope friction takes up to 5 times more fuel consumption than other frictions in short times, depending on the slope angle and slope parabolic vertical curve distances. IEMM can calculate how much energy is needed in each step, and works out a desired fuel rate for the engine so that the power brake would not be needed. Using Equation (7), the average fuel consumption for Simulation 1 was found to be around 7.94 liter $/ 100 \mathrm{~km}$.

B.2. Simulation Result 2: The power and fuel consumption results for the second simulation are shown in Fig. 7. Similarly, $8635 \mathrm{~W}$ of energy is initially given to the vehicle so that the initial speed of 


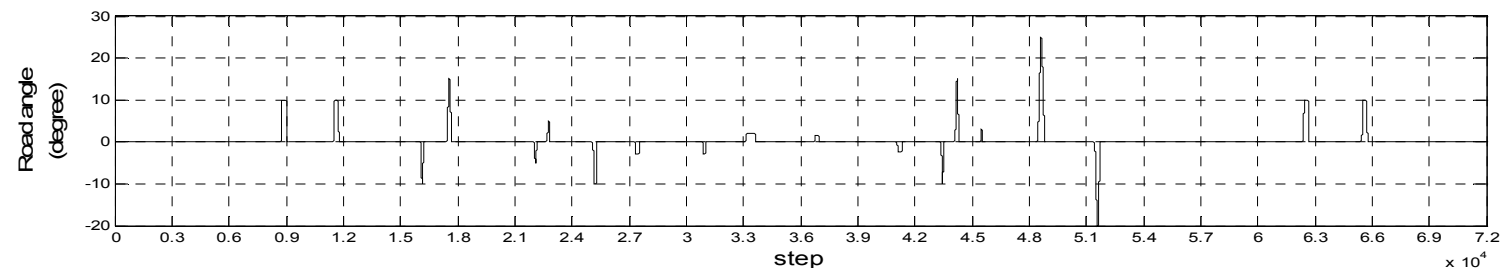

(a)

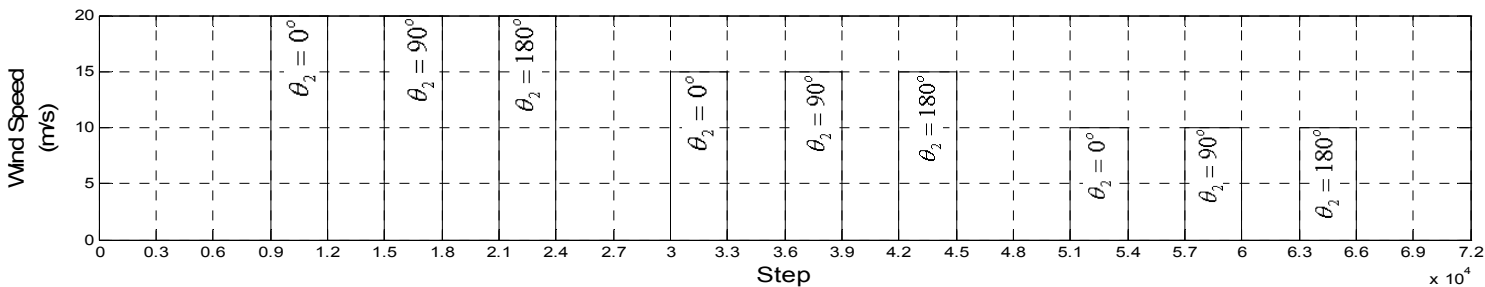

(b)

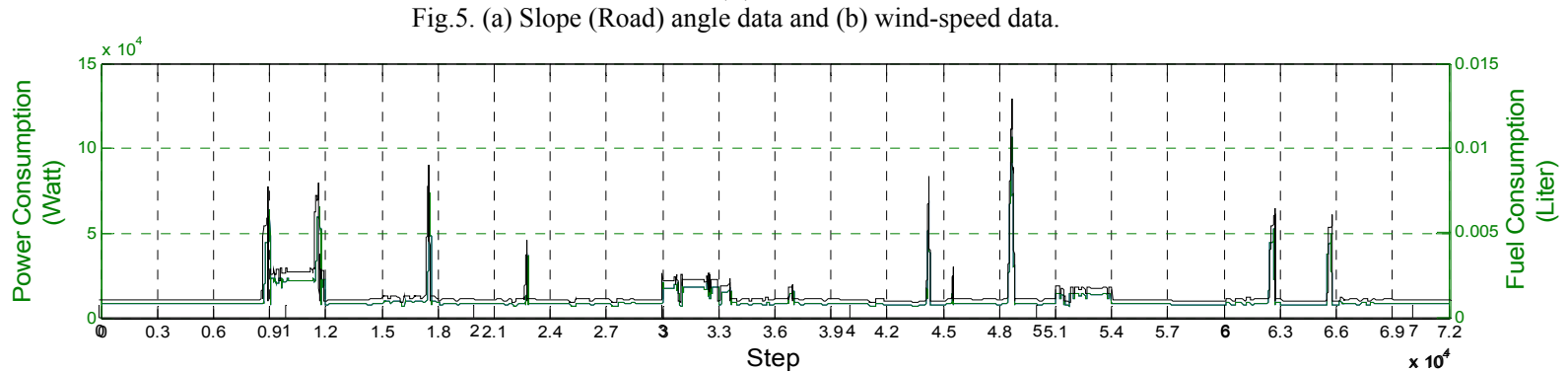

Fig 6. Power and fuel consumption results for Simulation 1.

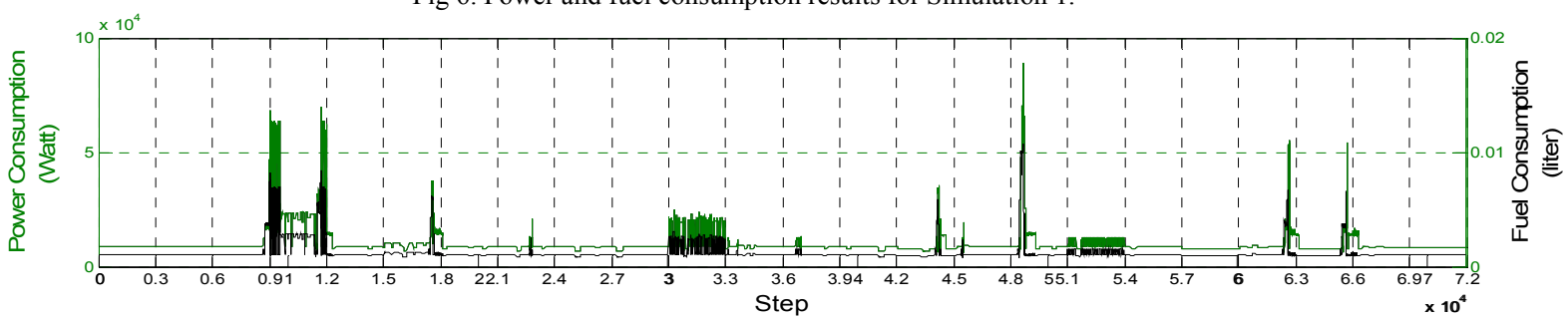

Fig.7. Power and fuel consumption results for Simulation 2.

$16.6 \mathrm{~m} / \mathrm{s}$ is achieved. Also, the SPU informed IEMM about any slope ahead.

IEMM calculates and investigates OPP, and if the load is found to be greater than $20 \mathrm{~kW}$ or the slope greater than $10^{\circ}$, for propulsion balance requests ILL to switch on EM through inverter. The outcome of this simulation shows that the vehicle speed and acceleration is smoother than that of Simulation 1. Using Equation (7), the average fuel consumption for Simulation 2 was found to be around 7.46 liter $/ 100 \mathrm{~km}$.

\section{CONCLUSIONS}

An intelligent energy management model was presented. The model takes into account the role of combined wind/drag, slope, rolling, and accessories loads to minimise the fuel consumption under various driving conditions. Two simulation studies were conducted. They show that the vehicle speed and acceleration was smoother where the hybrid section was included. The average fuel consumption for Simulation 1 and 2 were found to be around 7.94 and 7.46 liter $/ 100 \mathrm{~km}$, respectively.

\section{REFERENCES}

[1] R. Langari and J.S.W. Won, "Intelligent Energy Management Agent for a Parallel Hybrid Vehicle-Part 1: Systsem Architecture and Design of the Driving Situation Identification Process," IEEE Trasactions on Vehicular Technology, vol. 54, pp. 925-934, 2005.

[2] C. Grelle and L. Ippolito, "Agent-based architecture for designing hybrid control systems," information science vol. 176, pp. 1103-1130, 2006.

[3] M. Koot, J. T. B. A. Kessels, and B. D. Jager, "Fuel reduction potential of energy management for vehicular electric power systems " Int. J. Alternative Propulsion vol. 1, 2006.

[4] A. Poursamad and M. Montazeri, "Design of genetic-fuzzy control strategy for parallel hybrid electric vehicles," control engineering practice 2008.

[5] X. He, M. Parten, and T. Maxwell, "Energy management strategies for a Hybrid electric vehicle," IEEE pp. 536-540, 2005.

[6] M. Plint and A. Martyr, "Engine testing theory and practice," Butter worth-Heinemann British Library 1997.

[7] W. W. Pullkrabek, "Engineering fundamentals of the internal combustion engine, ," Prentice Hall 2003.

[8] L. L. Yaodong Wang, "An analytic study of applying Miller cycle to reduce Nox emission from petrol engine," Applied Thermal Engineering, vol. 27, pp. 1779-1789, 2007.

[9] J. B. Heywood, "Internal combustion engine fundamentals," McGrawHill, New York, 1998.

[10] G. J. v. Wylen and R. E. Sonntag, "Fundamentals of classical thermodynamics," vol. Third edition SI version 1990.

[11] T. N. Zeland, "State highway geometric design manual section 5: vertical alignment," Transit NewZeland, 2002. 